DOI: https://doi.org/10.30749/2594-8261.v3n1p27-33

\title{
A JURISPRUDÊNCIA DOS CONCEITOS E O NEOKANTISMO
}

\section{THE JURISPRUDENCE OF CONCEPTS AND THE NEOKANTISM}

André R.C. Fontes ${ }^{*}$

Resumo: A classificação e a correlação das formas do pensamento alemão de meados do século XIX até as ascensão do Nazismo é o objetivo deste artigo, com especial destaque para a contribuição dos juristas judeus e a sua contribuição para o Neokantismo. O texto também arrola os principais desdobramentos justeoréticos das Escolas relacionadas ao pensamento de Immanel Kant.

Palavras-Chave: Positivismo. Idealismo. Escola axiológica. Hegelianismo. Categorias fundamentais do Direito.

Abstract: Classification and correlation of German thought forms the mid-nineteenth century to the rise of Nazism is the purpose of this article, with special emphasis on the contribution of Jewish lawyers and their contribution to neokantianism. The text also lists the main theoretical law developments of schools related to the thought of Immanuel Kant.

Keywords: Positivism. School axiological. Hegelianism. Fundamental categories of law.

"Doutor em Direito Civil pela Universidade do Estado do Rio de Janeiro - UERJ (2005), Doutor em Ciências Ambientais e Florestais pela Universidade Federal Rural do Rio de Janeiro - UFRRJ (2015), Professor na Universidade Federal do Estado do Rio de Janeiro - UNIRIO e Desembargador no Tribunal Regional da $2^{\mathrm{a}}$ Região (Rio de Janeiro e Espírito Santo). 


\section{INTRODUÇÃO}

Pode-se assinalar três períodos particularmente relevantes no desenvolvimento do pensamento alemão no decurso do século XX: o Historicismo, o Positivismo e o Neokantismo. A Filosofia dos Conceitos inclui-se na terceira corrente. A despeito de todo antagonismo, penetrou no pensamento jurídico e edificou o grande sistema de conceitos na passagem do século. Apresentava-se, paralelamente, ao Pandectismo, mas com ele não se confundia. (LARENZ, 2012). ${ }^{1}$

As marcas da Escola Histórica do Direito se fazem presentes de variadas formas nas teorias desenvolvidas ao longo do século XIX, e todo o debate que provoca orienta algumas das discussões mais importantes no Século XX. Seus maiores representantes são Friedrich Carl von Savigny e seu aluno Georg Friedrich Puchta. A atitude anticodificadora para a legislação e os questionamentos sobre a concepção de lei são pontos de destaque nos seus estudos e análise, ao sustentar que o Direito é fruto das tradições e da história de cada povo e que sua contínua evolução e transformação não eram compatíveis com a sistemática férrea e rígida de uma codificação, nos moldes do Código Napoleão. Baseados nesses argumentos, Savigny travou conhecida polêmica com Thibaut sobre a codificação alemã. (WESENBERG; WESENER, 1998, p. 269; SAVIGNY, 1946; OERTMANN,1933, p. 17; PUCHTA, 1858).

Partindo de um debate sobre as origens do Direito alemão e da recuperação do Direito antigo, suscita uma releitura do significado de espírito do povo (o Volksgeist). Compenetrados nas ideias de que as leis e os códigos não estariam necessariamente em harmonia com o caráter do povo, acentuaram o desenvolvimento progressivo da Ciência do Direito e a necessidade de deixar fruir a tradição jurídica nacional. (WESENBERG; WESENER, 1998, p. 269; SCHMITT, [19--?]).

\footnotetext{
1 Para um exame específico sobre a noção de conceito em Direito: Du Paquier (1979, p 168) e Rodriguez (1994).
} 


\section{DESENVOLVIMENTO}

As concepções históricas brotaram no ambiente cultural e romântico alemão para demonstrar a natureza progressiva e, portanto, histórica, das manifestações e da lenta maturação do desenvolvimento do indivíduo concreto e histórico. E elas bem se mostraram na passagem do Historicismo para o século $X X$, ao provocar uma série de movimentos em torno da Filosofia de Hegel, conhecidos como neo-hegelianos, que pregam a ausência de critério objetivo para determinar a análise de um objeto de estudo, de modo que, por exemplo, a Filosofia, a Política e o Direito estariam fadados à sua própria historicidade. Esses movimentos, que se desdobram da filosofia de Hegel, seguem uma evolução que é contrária ao Positivismo, especialmente, pela exigência ética baseada em valores ideais que, por sua vez, acompanham a Filosofia transcendental de Kant, e que não é contrária ao Hegelianismo. (KERVÉGAN, 2006, p. 4$)^{2}$

Nas premissas históricas da formação e desenvolvimento da filosofia de Emmanuel Kant, a simplificação do estudo do seu pensamento nos conduziria à afirmação de que as ideias transformaram-se em Filosofia, que respondeu com a Filosofia da ideia que é englobada na denominação geral de Idealismo. (BOCHENSKI, 1968, p. 85). É uma das correntes filosóficas mais importantes do século XIX e avança até o primeiro quartel do século $X X$, quando parece perder importância. Sua área de influência é a Europa continental, a América do Sul, a América Central e o México. A despeito dos vários movimentos reputados idealistas, em todos os seus seguidores há o traço comum de serem idealistas em matéria epistemológica e em seus objetivos. Desse modo, toda a realidade é imanente a um espírito objetivo, o qual cria as formas que aparecem na natureza e na alma humana, ou que se identificam com ambas. (BOCHENSKI, 1968; HIRSCHBERGER, 1967, p. 273).

Ao se estabelecer que o pensamento não existe objetivamente interno e fixado de antemão, marchou-se num processo natural, objetivo e condicionado por causas concretas para uma série de movimentos renovadores. Esses movimentos

\footnotetext{
${ }^{2}$ Numa visão abrangente: Kant (1978) e Fouillée (1922. p. 33). 
eram sete ao todo, segundo classificação de alguns autores (que seguem arrolados e enumerados a seguir). E eram chamados de neokantistas ou neokantianos. Cinco foram logo superados, e sublinhamos que não eram kantianos ortodoxos. Dois, entretanto, que eram os mais importantes, não somente floresceram, como se mostraram muito ativos. Fiéis ao espírito de Kant, encontraram forte eco até mesmo no período dos dois grandes conflitos mundiais. (BOCHENSKI, 1968).

Seria justo conceber a ideia de que o desenvolvimento objetivo e a sucessão das formações de seus integrantes seguiram certo esquema filosófico-histórico exclusivamente alemão. A aparição de alguns expoentes na universalidade da filosofia mundial nos adverte, de maneira gráfica e simples, o sistema de pensamento de toda uma época, mas não exclui a debilidade de sua afirmação e a necessidade de agruparmos os pontos mais relevantes de cada movimento concentrados na Alemanha. (BOCHENSKI, 1968; AJDUKIEWICZ, 1979, p. 15).

As formas puras dos dois movimentos obriga a separação uma da outra. Nos últimos trinta anos do Século XIX, prevaleceu o idealismo. Podem ser enumeradas, da seguinte forma, as escolas Neokantianas (BOCHENSKI, 1968, p. 98) ${ }^{3}$ :

(1) Fisiologista;

(2) Metafísica;

(3) Realista;

(4) Relativista;

(5) Psicológica;

(6) Axiológica;

(7) Logicista;

A escola fisiologista buscava a interpretação das formas kantianas a priori como disposições filosóficas. (BOCHENSKI, 1968, p. 98). Seus principais integrantes são Hermann Helmholtz (1821-1894) e Friedrich Albert Lange (1828-1875). (BOCHENSKI, 1968, p. 98; HIRSCHBERGER, 1967, p. 62). A escola metafísica admitia a possibilidade de uma metafísica crítica e era formada, basicamente, por Otto

\footnotetext{
${ }^{3}$ A classificação é de Bochenski (1968). 
Leibmann (1840-1912) e por Joahannes Volkelt (1848-1930). (BOCHENSKI, 1968, p. 98; HIRSCHBERGER, 1967, p. 129). A escola realista manifestava-se no sentido da existência de uma coisa em si e encontrava expressão em Alois Riehl (1844-1924) e Richard Hönigswald (1875-1947). (BOCHENSKI, 1968, p. 98). A escola relativista sustentava que o a priori kantiano era de natureza psicológica e relativa, e encontrava em Georg Simmel (1858-1918) seu mais original e principal representante. ${ }^{4} \mathrm{~A}$ escola psicológica, conduzida por Hans Cornelius (1863-1947) se aproximava ainda mais do Positivismo. ${ }^{5}$

Ao se elevarem à categoria de neokantianas, essas escolas não eram ortodoxas e foram logo superadas. A sua vez, as duas, que se mantiveram verdadeiramente orientadas pelo espírito de Kant, foram a Escola Logicista, de Marburgo, e a Escola Axiológica, de Baden. (BATALHA; RODRIGUES NETTO, 2000, p. 171; AJDUKIEWICZ, 1979, p. 15; REALE, 2007, p. xxx; GALEFFI, 1986. p. 191; FOULLÉE, 1909, p. 17; LA TORRE, 2006, p. 15).

\section{CONCLUSÃO}

À medida que ascendia o Nazismo, essas duas escolas desapareceram. Isso porque a maior parte de seus representantes era de origem judaica e foram, como é sabido, violentamente perseguidos, afastados da vida acadêmica e cultural da Alemanha ou, simples e aterradoramente, assassinados. O reinado do NacionalSocialismo desferiu-Ihes, portanto, o golpe de morte. Sem renovação e sem novos estudiosos, tornou-se hoje mais uma referência crítica como centro de dogmatismos ou mesmo de sectarismo dogmático, mas que não podem deixar de ser mencionados, especialmente pela sua repercussão no Direito. Figura importantíssima do movimento no Direito é Rudolf Stammler que, por meio das suas conhecidas categorias

\footnotetext{
${ }^{4}$ Georg Simmel era um historicista (não-biologizante) kantiano relativista e original. (BOCHENSKI, 1968, p. 124). A lista de pensadores influenciados por Georg Simmel é extensa. Na verdade Simmel é um ilustre representante da Sociologia formal com um rol não determinado de seguidores e, também, da Sociologia Urbana, que tanta influência teve nos EUA. Cf. JANKÉLÉVITCH, Vladimir. Georg Simmel, filósofo de la vida. Trad. de Antonia García Castro. Madri: Gedisa, 2007. Cf. (BOCHENSKI, 1968, p. 98).

${ }^{5}$ Hans Cornelius muito influenciou Max Horkeheimer e Theodor Adorno. (AJDUKIEWICZ, 1979, p. 64; SCIACCA, 1968, p. 168; REALI; ANTISERI, 1991; BOCHENSKI, 1968, p. 124).
} 
fundamentais do Direito, posssibilitou o grande e derradeiro suspiro do Neokantismo logicista da Escola de Marburgo. (BOCHENSKI, 1968, p. 98; REALI; ANTISERI, 1991; SMEND, 1988; MULLER, 2009; BONNARD, 1939, 1940; SALDANHA, 2005; STAMMLER, 2008; LA TORRE, 2006, p. 15).

\section{REFERÊNCIAS}

AJDUKIEWICZ, Kazimierz. Problemas e teorias da filosofia. Trad. Pablo Rubén Mariconda e Regina Correa Rocha. São Paulo: Livraria Editora Ciências Humanas, 1979.

BATALHA, Wilson de Souza Campos; RODRIGUES NETTO Sílvia Marina L. Batalha de. Filosofia jurídica e história do Direito. Rio de Janeiro: Forense, 2000.

BOCHENSKI, I.M. A filosofia contemporânea ocidental. 2. ed. Trad. de Antônio Pinto de Carvalho. São Paulo Herder, 1968.

BONNARD, Roger. Le droit et l'État dans la doctrine national socialiste. 2. ed. Paris: Librairie Générale de Droit, 1939.

BONNARD, Roger. La guerre de 1939-1940 et lê droit public. Paris: Librairie Générale de Droit e Jurisprudence, 1940.

DU PAQUIER, Claude. Introduction à la théorie générale et à la philosophie du Droit. Neuchatel: Delachaux \& Niestlé, 1979.

FOUILLÉE. Novisimo concepto del derecho. Trad. Eduardo Gómez de Baquero. Madri: La España Moderna, 1909.

GALEFFI, Romano. A filosofia de Immanuel Kant. Brasília: Universidade de Brasília, 1986.

HIRSCHBERGER, Johannes. História da filosofia moderna. 2. ed. Trad. Alexandre Correia. São Paulo: Herder, 1967.

KANT, I. Introduccion a la teoria del derecho. Trad. Felipe Gonzalez Vicen. Madri: Centro de Estudios Constitucionales, 1978.

KERVÉGAN, Jean-François. Hegel, Carl Schmitt. Trad. Carolina Huang. São Paulo: Manole, 2006.

LARENZ, Kar. Metodologia da Ciência do Direito. Lisboa: Fundação Calouste Gulbenhian, 2012. 
LA TORRE, Massimo. La crisi del novecento: giuristi e filosofi nel creposcolo di Weimer. Bari: Dedalo, 2006.

MULLER, Ingo. Los juristas del horror. Trad. Carlos Armando Figueredo. Bogotá: Álvaro Nora, 2009.

OERTMANN, Paul. Introducción al derecho civil. Trad. Luis Sancho Seral. Barcelona: Labor, 1933.

PUCHTA, Georg Friedrich. Storia del diritto presso il popolo romano. Trad. Carlo Poli. Milão: Stabelecimento Civelli Giuseppe, 1858.

REALE, Miguel. Filosofia do Direito. 20. ed. São Paulo: Saraiva, 2007.

REALI, Giovanni; ANTISERI, Dario. História da Filosofia. v. 3. Trad. Álvaro Cunha. São Paulo: Paulinas, 1991.

RODRIGUEZ, Carlos Eduardo López. Introdução ao pensamento e à obra jurídica de Karl Larenz. Porto Alegre: Livraria do Advogado, 1994.

SALDANHA, Nelson. Da Teologia a metolodogia. Belo Horizonte: Del Rey, 2005.

SAVIGNY, F. de. De la vocación de nuestro siglo para la legislación y para la ciencia del derecho. Trad. Adolfo G. Posada. Buenos Aires: Editorial Avalaya, 1946.

SCIACCA, Michele Federico. História da Filosofia. Trad. Luís Washington Vita. São Paulo: Mestre Jou, 1968.

SCHMITT, Carl. Teoria de la constitución. Trad. Francisco Ayala. Buenos Aires: Struhart \& Cia., [19--?]. p. 389.

SMEND, Rudolf. Costituzione e diritto costituzionale. Trad. F. Fiore e J. Luther. Milão: Giuffrè, 1988.

STAMMLER, Rudol. Tratado de filosofia del derecho. México: Coyoacán, 2008.

WESENBERG, Gerhard; WESENER, Gunter. Historia del derecho privado moderno em Alemania y em Europa. Trad. José Javier de los Mozos Touya. Valadoli: Lex Nova, 1998. 